\title{
WATER QUALITY TRADING: A CONCEPTUAL FRAMEWORK FOR INCORPORATING ANCILLARY BENEFITS
}

\author{
JUHN-YUAN SU ${ }^{1}$, MICHAEL E. BARBER ${ }^{1} \&$ ROBERT L. MAHLER ${ }^{2}$ \\ ${ }^{1}$ Civil and Environmental Engineering, University of Utah, Salt Lake City, UT, U.S.A. \\ ${ }^{2}$ Soil Science Division, University of Idaho, Moscow, ID, U.S.A.
}

\begin{abstract}
Water quality trading (WQT) has been proposed as a mechanism for improving surface water quality goals in an economically and socially responsible manner. However, to date, successful markets for WQT have been slow to develop with many interested parties pointing to the need for aggressive regulatory enforcement of standards as a key requirement in the trading process. As regulations in the United States and many other countries typically apply to impaired waterways, the inherent problem with this as the only driver for trades is that little to no value is prescribed to raising water quality to above minimum standards. Because numerous studies have shown the economic value of improved ecosystem services and our own work with public surveys that demonstrated the importance of water quality, we hypothesize that an informed public (as well as aquatic ecosystem managers) will place additional value on water quality conditions that exceed minimum values. We present a framework for incorporating this concept into the WQT process that already includes essential elements such as trading ratios, uncertainty, and evaluation. We demonstrate the framework approach using a StreeterPhelps dissolved oxygen (DO) model to address a recognized DO problem in the Jordan River in Utah, USA. It is recognized that this work represents the initial discussion of the process and that adaptive management of the complex processes will be needed in order to maximize the sustainable of water resources.

Keywords: Dissolved Oxygen, Total Maximum Daily Load; Streeter-Phelps Equation, US Environmental Protection Agency (US EPA), Water Quality Trading.
\end{abstract}

\section{INTRODUCTION}

The concept of market-based water quality trading (WQT) has been around for decades although there have been relatively few successfully implemented trades compared to the enormous potential [1], [2]. In spite of limited initial success, water quality policymakers and local stakeholder groups show continued and growing interest in the concept of WQT [3]. In examining existing trading schemes from around the globe, Selman et al. identified five key factors for the successful implementation of WQT programs: (1) strong regulatory/nonregulatory drivers to create a market for water quality credits; (2) robust, consistent, and standardized estimation methodologies for nonpoint source actions; (3) buy-in from local and state stakeholders; (4) standardized tools, transparent processes, and online registries to minimize transaction costs; and (5) minimal potential liability risks to the regulated community from meeting regulations through trades [4]. In the United States, the US Environmental Protection Agency (USEPA) requires credible trading programs to have seven common elements including: a common unit of trade, an understanding of the timing of credits, appropriate trading ratios for managing uncertainty, compliance and enforcement mechanisms, public notification, program evaluation, and legal authority [5]. The limitation to transactions requiring regulatory drivers for trades is that there is no benefit prescribed to trades that raising water quality to levels above minimum standards or benefit stream reaches that are not currently listed as impaired. While implementation of total maximum daily load (TMDL) processes in the United States may create more opportunities for WQTs, this alone may be 
insufficient in terms of developing a robust and sustainable trade market. Numerous studies have identified ancillary benefits to water quality improvements both in terms of ecosystem services and aesthetic property valuations [6], [7], [8]. A mechanistic process for incorporation these benefits into a WQT framework is needed to facilitate additional, economically prudent, solutions. This paper demonstrates a novel approach as to how such a framework could be established.

\section{BACKGROUND}

2.1 Overview of the total maximum daily load process and trading ratios

An expanding regulatory driver in the United States stems from the TMDL process. Section 303(d) of the Clean Water Act requires states to identify waters that do not meet water quality standards and to develop effluent limitation plans for reducing both point and nonpoint source loads. This is accomplished by conducting a TMDL study to determine the maximum amount of pollutant a stream segment could receive and still meet its designated beneficial use. The total load is determined by

$$
\mathrm{TMDL}=\mathrm{WLA}+\mathrm{LA}+\mathrm{MOS}
$$

where WLA is the waste load allocation, LA is additional nonpoint sources, and MOS is the margin of safety. WLAs are the pollutant loads allocated to current and future point sources including Municipal Separate Storm Sewer System (MS4) and other permit-recognized nonpoint sources.

Improvements to water quality have traditionally been accomplished through reductions in the WLA piece of the loading because of the legal authorities granted to regulatory agencies. While WQTs can occur within the WLA segment (e.g. stormwater vs wastewater outfalls), proposed exchanges between the WLA and LA segments are also possible. However, the uncertainty with regard to pollutant reduction in nonpoint or stormwater best management practices (BMPs) may require trading ratios greater than 1:1. The state of Minnesota reports trade ratios of up to 2.6:1 for nonpoint reduction for a WQT with a wastewater treatment facility [9]. Idaho's guidance document sets 1.5:1 as the minimum ratio [10]. Meanwhile, in establishing these trading ratios, all parties should consider where the pollutant reduction occurs. Pollutant reduction projects that occur considerably upstream of the actual discharge location have the capacity to improve miles of river quality. For instance, Wisconsin's guidance document describes the following conceptual equation for deriving a trading ratio that combines upstream and downstream characteristics with adjustments to habitat and water quality constituent [11].

$$
\mathrm{TR}=(\text { Del. }+ \text { Down. }+ \text { Equi. }+ \text { Uncert. }- \text { Hab. }): 1 .
$$

where TR is the trading ratio, Del. indicates the delivery, Down. represents downstream characteristics, Equi. is the equivalency adjustment based on water quality constituent, Uncert. is the uncertainty, and Hab. is the habitat adjustment.

2.2 Public perspective on water quality issues and improvement

Water quality issues pose major concerns toward evaluating the effects upon environmental, ecological, and societal characteristics. Consequently, general understanding over the 
public perspective of such water quality issues, along with the need of clean water, is needed toward evaluating such issues and potentially deriving remedies (e.g. water quality modelling, TMDL studies, etc.). For instance, Mahler et al. conducted intensive surveys over the Pacific Northwest for evaluating the public perspective over water quality issues of distinct forms of water (e.g. groundwater, rivers, etc.), along with the different uses of water (e.g. irrigation, drinking water, etc.) [12]. In these public surveys, the respondents were asked to identify each issue in water quality (drinking water, rivers, groundwater, water for agriculture, water for power generation, water for economic development, wetland loss, salmon extinction, watershed restoration, and recreational use) as extremely important, very important, somewhat important, not important, or having no opinion [12]. The following table provides such survey results over the percent of respondents that identify each distinct water use or water form as extremely important or very important [12].

As displayed in Table 1, such survey results suggest the emphasis of clean water for all water uses, yielding at least $55 \%$ of respondents identifying each water use as very or extremely important. For instance, according to Table 1, such public surveys suggest the emphasis of clean water quality for rivers and groundwater, with $94 \%$ and $93 \%$ of respondents identifying clean rivers and clean groundwater, respectively, as very or extremely important. Such survey results hence suggest the public value of clean water, emphasizing the need for analysis and possible remedies against any major water quality issues. Meanwhile, as a result of intensive public surveys, Mahler and Barber have shown that adult education can be successful in driving adoption of water quality improvements in nonregulatory environments [13]. In 2015, the Utah Division of Water Quality (UDWQ) conducted a targeted survey of stakeholders that included partner agencies, regulated entities, and others that also demonstrated the public's attitude towards water quality [14]. In response to the statement 'A water quality project that provides additional benefits to wildlife

Table 1: Percent of survey respondents, with 928 total, along the Pacific Northwest, United States, ranking the surveyed water issues as very or extremely important.

\begin{tabular}{lc}
\hline Water use & $\begin{array}{c}\text { Percent of respondents recognize as } \\
\text { very or extremely important }\end{array}$ \\
\hline Clean drinking water & 99 \\
Clean rivers & 94 \\
Clean groundwater & 93 \\
Water for agriculture & 84 \\
Water for power generation & 72 \\
Water for economic development & 70 \\
Loss of wetlands (wildlife habitats) & 69 \\
Prevention of salmon extinction & 69 \\
Watershed restoration & 68 \\
Water for recreation (fishing, boating, etc.) & 58 \\
\hline
\end{tabular}


and watersheds should be considered in prioritizing improvement efforts,' an overwhelming $90 \%$ strongly agreed or agreed whereas only $2.2 \%$ disagreed or strongly disagreed. While perhaps not universally representative of the general Utah population due to its directed contact approach rather than randomly distributed questionnaires, of the 427 respondents, 245 identified themselves as concerned citizens as opposed to state agency personnel (101), local government (95), education (90), researchers (74), advocacy groups (47), and federal government (44).

\subsection{Case study: Jordan River watershed in Salt Lake City, UT}

The Jordan River near Salt Lake City, Utah, is used as a case study for the WQT framework. The Jordan River involves an approximate 82.7-kilometer, 51-mile reach that flows from south to north and discharges into the Great Salt Lake. Figure 1 displays the Jordan River system with the tributary inflows, wastewater treatment plants (WWTPs), and the diversion of interest for the framework, along with the Jordan River's location in the United States.

As indicated in Fig. 1, the Jordan River receives major tributary inflows from Little and Big Cottonwood Creek, along with four WWTPs (Jordan Basin, South Valley, Central Valley that is combined with Millcreek, and South Davis South). The Surplus Canal, located approximately $2 \mathrm{~km}$ downstream of the Central Valley WWTP and Millcreek, diverts a significant amount of flow from the Jordan River. Portions of the Jordan River have been indicated as impaired due to distinct water quality constituents, particularly the Jordan River downstream of the Surplus Canal (Fig. 1) that is identified as impaired due to dissolved oxygen (DO) [14].

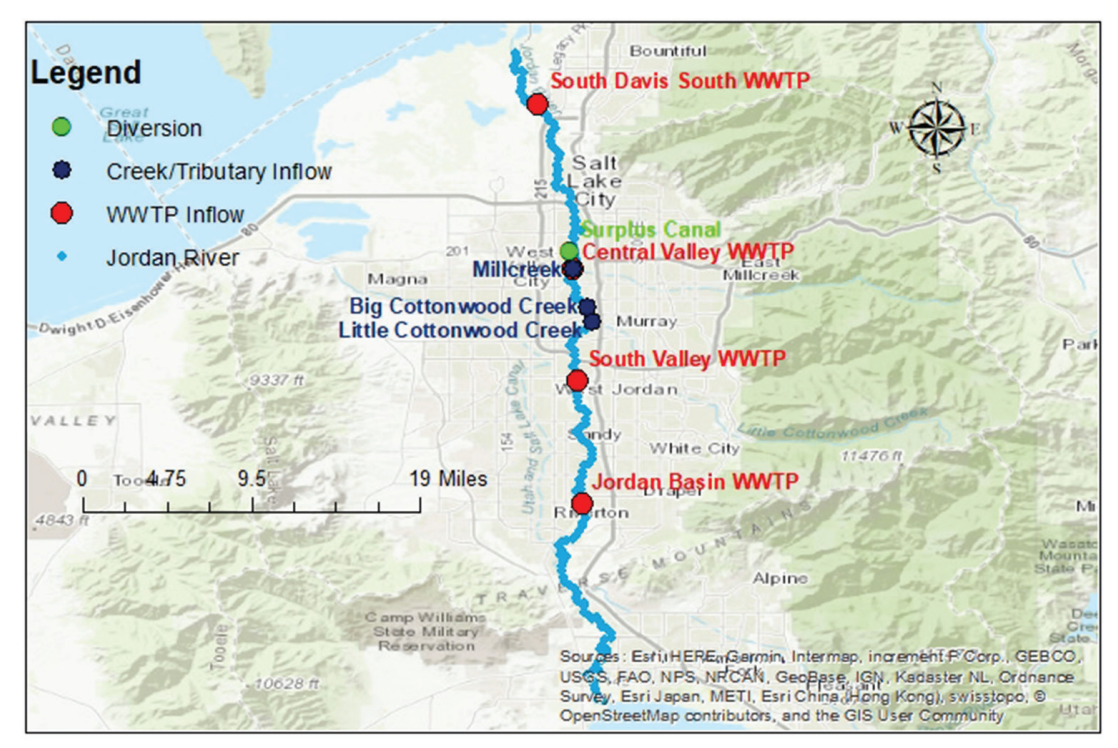

(a) 


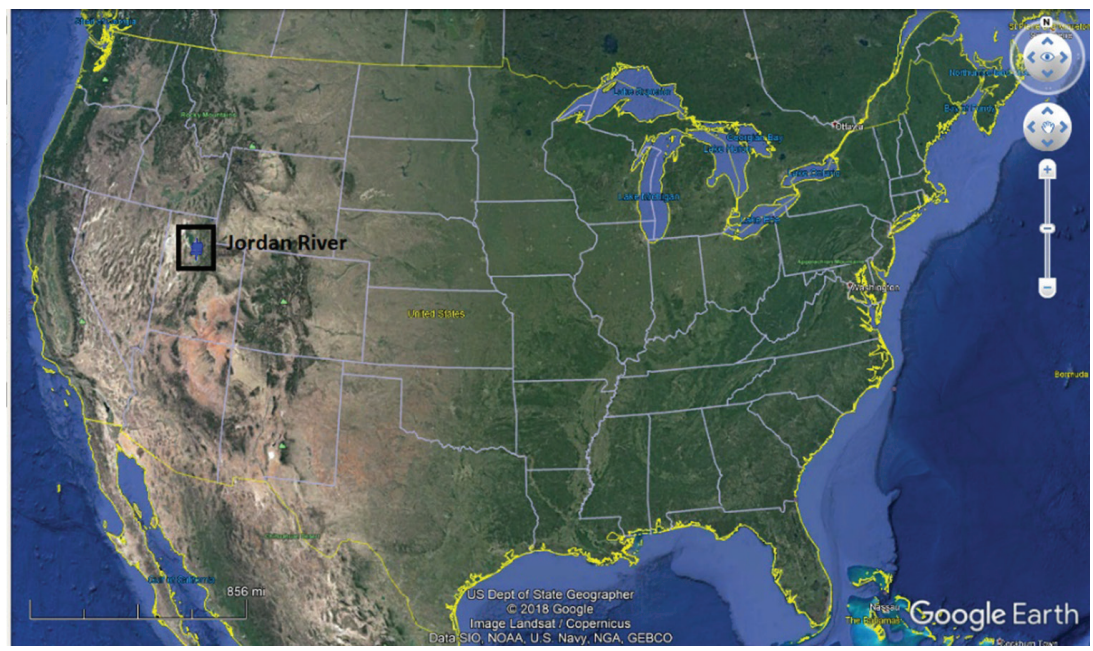

(b)

Figure 1: Jordan River in Salt Lake City, UT. (a) Jordan River with tributary inflows, WWTP inflows, and diversion; (b) Jordan River location in the United States.

\section{METHODOLOGY}

\subsection{Streeter-Phelps model for DO}

The well-known Streeter-Phelps equation for DO concentrations, C $[\mathrm{mg} / \mathrm{L}]$, is generally written as:

$$
C=C_{s}-\left\{\frac{k_{d} L_{0}}{k_{a}-k_{r}}\left[e^{-\frac{k_{r}}{U} x}-e^{-\frac{k_{a}}{U} x}\right]\right\}-\left(C_{s}-C_{0}\right) e^{-\frac{k_{a}}{U} x}
$$

where $c_{s}$ is the DO concentration at saturation, $C_{0}$ the initial DO concentration, $k_{a}$ the reaeration constant, $k_{d}$ the rate of oxidation of the carbonaceous material, $k_{s}$ the BOD settling rate, $k_{r}=k_{d}+k_{s}$ (decomposition and settling), $L_{0}$ the initial BOD concentration, $U$ the water velocity, and $x$ is the downstream distance. Meanwhile, the reaeration and the rate of oxidation are dependent on water temperature. For instance, oxygen reaeration rates established for water at $20^{\circ} \mathrm{C}$ can be extrapolated using:

$$
k_{a, T}=k_{a, 20} \theta^{T-20} .
$$

where $k_{a, 20}$ indicates the reaeration rate at $20^{\circ} \mathrm{C}, k_{a, T}$ is the reaeration rate at a water temperature, $T$, and $\theta$ is the temperature-correction coefficient for reaeration that is approximated as 1.024 [15]. The rate of oxidation is adjusted similarly based on water temperature 
as those for reaeration (e.g. eqn. (4)) but with a temperature-correction coefficient for oxidation of 1.047 based on the oxidation rate at $20^{\circ} \mathrm{C}$ approximated as 0.2 per day [16]. For this exercise, the reaeration rate at $20^{\circ} \mathrm{C}, k_{a, 20}$, under units per day is approximated by the O'Connor-Dobbins Model that is a function of the water velocity $U$ (in metres per second) and the water depth $H$ (in meters) as follows.

$$
k_{a, 20}=3.93\left(\frac{U^{0.5}}{H^{1.5}}\right) .
$$

At the same time, the DO concentration at saturation, $c_{s}$, is computed as a function of water temperature, $T$, using:

$$
\ln c_{s}=-139.344+\frac{1.576 * 10^{5}}{T}-\frac{6.642 * 10^{7}}{T^{2}}+\frac{1.244 * 10^{10}}{T^{3}}-\frac{8.622 * 10^{11}}{T^{4}} .
$$

Meanwhile, the water temperature $T$, initial DO concentration $\mathrm{C}_{0}$, and the initial BOD concentration $\mathrm{L}_{0}$ are computed based on elemental mass balance per segment, incorporating headwater (upstream boundary), point source inflow, and any tributary/nonpoint source inflows. The following relationship is applied for an elemental mass balance for computing $Y_{0}$, which can be water temperature, initial DO concentration $C_{0}$, or the initial BOD concentration $L_{0}$, based on headwater, point source, and tributary/nonpoint source.

$$
Y_{0}=\frac{Q_{H} Y_{H}+Q_{P} Y_{P}+Q_{T} Y_{T}}{Q_{H}+Q_{P}+Q_{T}} .
$$

where $Q_{H}$ and $Y_{H}$ represent the discharge and parameter (water temperature, initial BOD concentration, or initial DO concentration) from the headwater/upstream boundary, respectively; $Q_{P}$ and $Y_{P}$ indicate the discharge and parameter from the point source, consecutively; and $Q_{T}$ and $Y_{T}$ is the discharge and parameter from tributary/nonpoint source, correspondingly. For the headwater/upstream boundary BOD and DO (indicated as parameter $Y_{H}$ in eqn (7)), a segment that exhibits a point source and/or tributary/nonpoint source inflow applies the BOD concentration $L$ and implements the Streeter-Phelps model (eqn (3)) for the headwater DO concentration at directly upstream of the segment toward employing such elemental mass balance for re-calculating $L_{0}$ and $C_{0}$ (eqn (7)). Such adjustment for BOD is applied by calculating the BOD concentration $L$ as exhibiting a first-order oxidation rate $k_{d}$ as a function of distance $x$ by the following relationship:

$$
L=L_{0} e^{-k_{d} x}
$$

\subsection{WQT framework as a spreadsheet model}

For this exercise, a spreadsheet model has been developed for the WQT framework, incorporating wastewater discharges, the major tributaries, etc. The spreadsheet model applies the Streeter-Phelps DO Model (eqn (3)) and then the first-order decay model for BOD (eqn (8)) based on no levels of removal applied followed by the DO model with user-defined removal levels on point source + tributary flow and BOD. The percent difference $E$ is calculated 
among the concentration without removal and the concentration with user-defined removal through the following relationship:

$$
E=100\left(\frac{C_{R}-C_{N R}}{C_{N R}}\right) .
$$

where $C_{N R}$ and $C_{R}$ indicate the concentration of DO or BOD without and with user-defined levels of removal of BOD or flow, respectively. In this exercise, the spreadsheet model applies a trapezoidal cross-section, yielding the following relationship for discharge into segment $Q$.

$$
Q=\frac{C_{f}}{n}\left(\frac{\left(\left(b+0.5 y\left(m_{1}+m_{2}\right)\right) y\right)^{\frac{5}{3}}}{\left(b+y \sqrt{1+\left(m_{1}\right)^{2}}+y \sqrt{1+\left(m_{2}\right)^{2}}\right)^{\frac{2}{3}}}\right) \sqrt{S},
$$

where $\mathrm{C}_{\mathrm{f}}$ is the coefficient for the Manning's Equation and is dependent on system of units (e.g. $C_{f}=1$ under SI units); $n$ is the Manning's roughness coefficient; $y$ indicates the water depth of channel; $b$ is the bottom width of channel; $m_{1}$ and $m_{2}$ represent the channel side slopes as the number of horizontal units against 1 vertical unit; and $S$ is the channel bottom slope that is approximated as parallel to the slope of the energy grade line (EGL). For this exercise, since the water depth $y$ from eqn (10) needs to be computed as the segment inflow $Q$ serves as an input, eqn (10) is calculated iteratively by applying an initial guess $y_{i}$ followed by re-calculated $y_{i+1}$ through the following manipulated form of eqn (10):

$$
y_{i+1}=\left(\frac{Q n}{\sqrt{S}}\right)^{\frac{3}{5}}\left(\frac{\left(b+y_{i} \sqrt{1+\left(m_{1}\right)^{2}}+y_{i} \sqrt{1+\left(m_{2}\right)^{2}}\right)^{\frac{2}{5}}}{b+0.5 y_{i}\left(m_{1}+m_{2}\right)}\right) .
$$

The spreadsheet model applies an initial guess of the water depth of $0.001 \mathrm{~m}$, computes the subsequent value for the water depth by eqn (11), and then repeats eqn (11) using the subsequent value for re-calculating the water depth. In this exercise, 150 iterations of eqn (11) have been implemented for numerically computing the water depth, which the value at the 150th iteration is employed for calculating the reaeration rate at $20^{\circ} \mathrm{C}$ (e.g. eqn (5) with $H$ as the channel water depth).

\subsection{Data sources for the case study on the Jordan River}

For this exercise, the spreadsheet model allows the user to input headwater inflow quantity and quality (e.g. upstream boundary conditions for the system), point source quantity and quality, tributary/nonpoint source quantity and quality, and flow diverted from the system. At the same time, the spreadsheet model allows the user to specify levels of removal upon inflow quantity and BOD concentration for point sources (e.g. WWTPs) and tributaries/nonpoint sources. Table 2 provides the references employed for retrieving DO, BOD, water temperature, and 
Table 2: Inflow quantity and quality (BOD, DO, water temperature) data reference for headwater, point sources, tributary/nonpoint sources, and diversions for the Jordan River.

\begin{tabular}{|c|c|c|}
\hline $\begin{array}{l}\text { Inflow headwater, } \\
\text { point source, } \\
\text { tributary, diversion }\end{array}$ & $\begin{array}{l}\text { Data employed (site no, } \\
\text { DMR, etc.) }\end{array}$ & Agency for data reference \\
\hline Upstream boundary & $\begin{array}{l}4994790 \text { (Jordan R at Utah L } \\
\text { Outlet U121 Xing) }\end{array}$ & Utah Division of Water Quality \\
\hline Jordan Basin WWTP & Discharge monthly report & Utah Division of Water Quality \\
\hline South Valley WWTP & Discharge monthly report & Utah Division of Water Quality \\
\hline $\begin{array}{l}\text { Little Cottonwood } \\
\text { Creek }\end{array}$ & $\begin{array}{l}4993580 \text { (Little Cottonwood } \\
\text { Ck } 4900 \text { S } 600 \text { W SLC) }\end{array}$ & Utah Division of Water Quality \\
\hline Big Cottonwood Creek & $\begin{array}{l}4992970 \text { (Big Cottonwood } \\
\text { Ck ab Jordan R at } 500 \mathrm{~W} \\
4200 \mathrm{~S} \text { ) }\end{array}$ & Utah Division of Water Quality \\
\hline Central Valley WWTP & Discharge monthly report & Utah Division of Water Quality \\
\hline Millcreek & $\begin{array}{l}4992480 \text { (Mill Creek above } \\
\text { Confl/Jordan River) }\end{array}$ & Utah Division of Water Quality \\
\hline Surplus Canal & $\begin{array}{l}10170500 \text { (Surplus Canal at } \\
\text { Salt Lake City, UT) }\end{array}$ & $\begin{array}{l}\text { United States Geological Survey } \\
\text { (USGS) }\end{array}$ \\
\hline $\begin{array}{l}\text { South Davis South } \\
\text { WWTP }\end{array}$ & Discharge Monthly Report & Utah Division of Water Quality \\
\hline
\end{tabular}

inflow quantity data for populating the headwater, point source, tributaries, and diversions for the Jordan River.

\section{RESULTS AND DISCUSSION}

4.1 DO and BOD concentrations on a selected case study time period

The spreadsheet model has been applied toward the Jordan River, selecting a time period during the summer/fall for which higher temperatures and lower inflows are observed. For this exercise, the spreadsheet model employs the headwater, point source, tributary, and diversion data for August 22, 2012. Meanwhile, for evaluating the effects of user-defined removal upon the DO concentration of the system, a removal of $80 \%$ is implemented upon the point source inflow quality for BOD while a $50 \%$ is applied toward tributary/nonpoint source inflow for BOD. Figure 2 displays the BOD and DO concentrations along the Jordan River without and with user-defined (80\% upon WWTP BOD; 50\% upon tributary/nonpoint source BOD) removal.

Meanwhile, Figure 3 display the percent differences in BOD and DO concentrations along the Jordan River for August 22, 2012 when applying 80\% point source BOD and 50\% tributary/nonpoint source BOD removal relative to the BOD and DO concentrations with no removal applied. 
BOD and DO Concentrations along Reach with and without User-Specified Removal

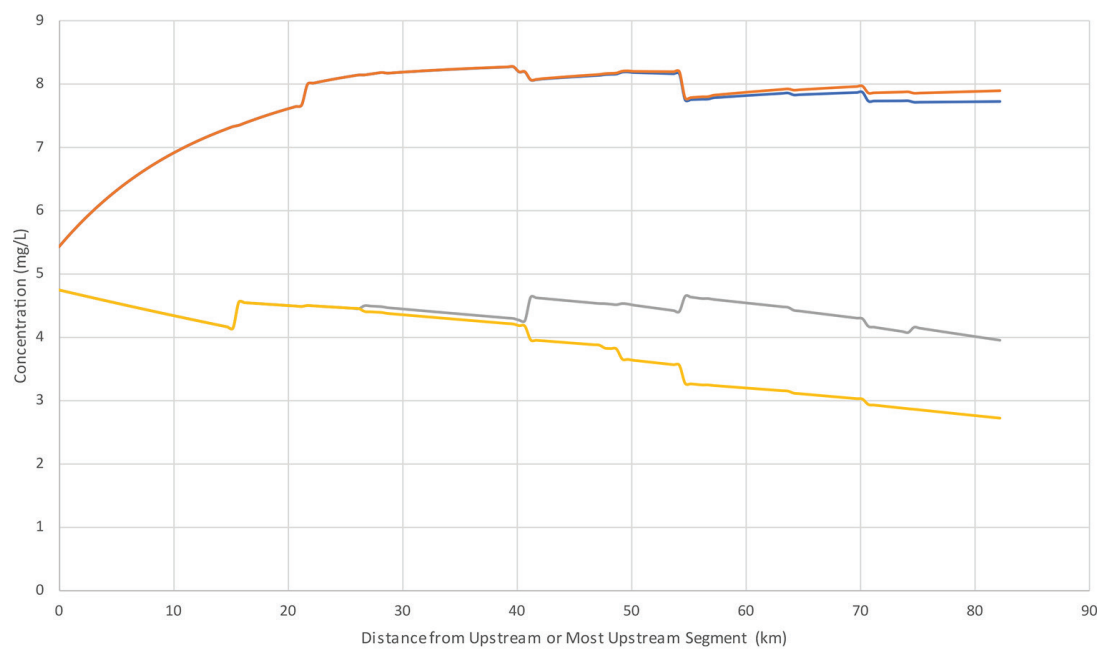

-DO- No Removal _ DO- User-Defined Removal _ BOD- No Removal _ BOD-User-Defined Removal

Figure 2: BOD and DO Concentrations along the Jordan River for August 22, 2012 without and with user-defined removal at $80 \%$ WWTP BOD removal and $50 \%$ tributary/nonpoint source BOD removal.

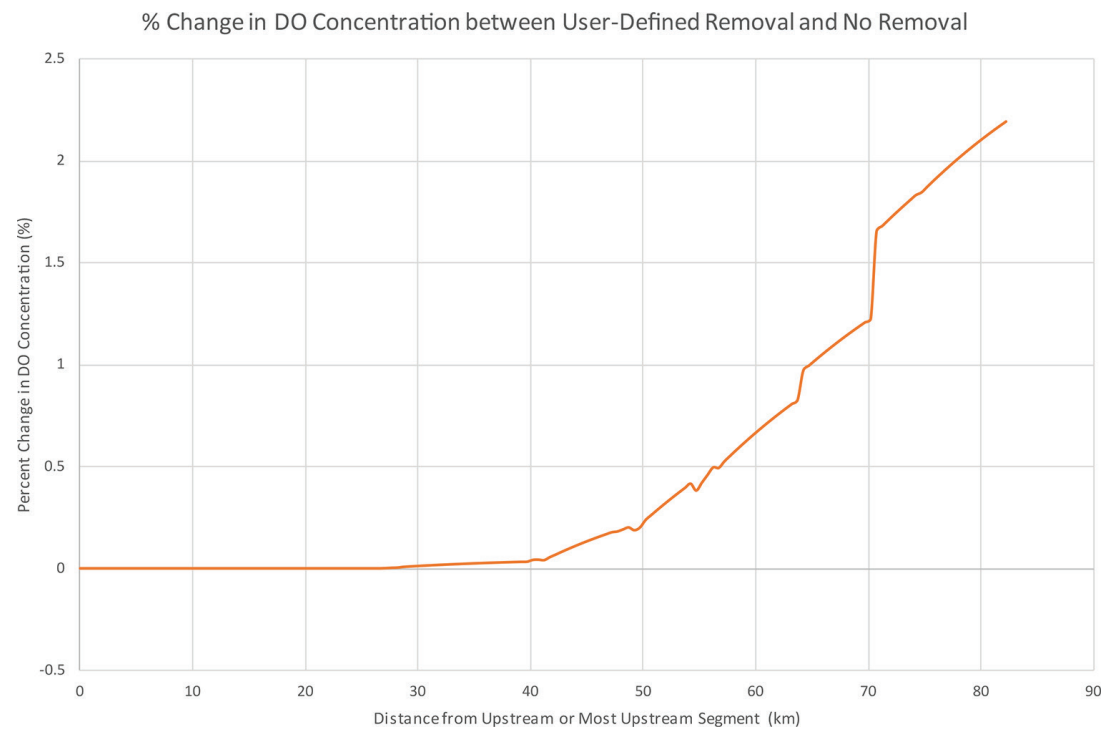

(a) 


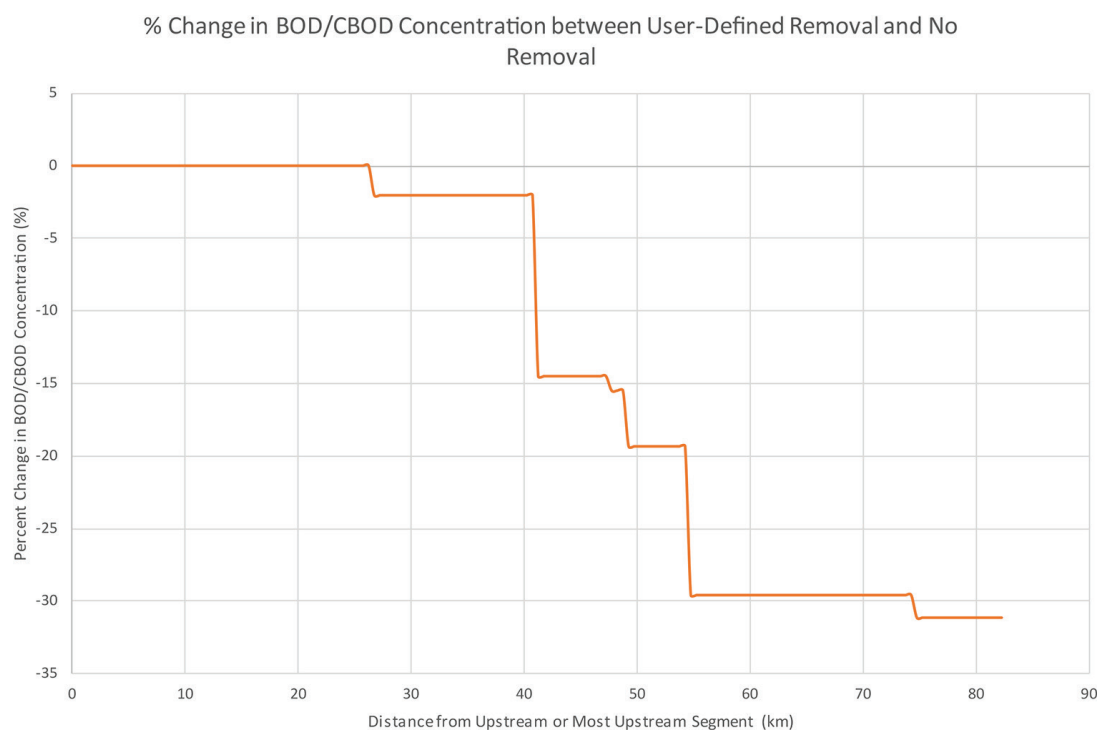

(b)

Figure 3: Percent difference in concentration for $80 \%$ point source BOD and 50\% tributary/nonpoint source BOD removal relative to no removal along the Jordan River on August 22, 2012. (a) Percent difference in DO concentration; (b) Percent difference in BOD concentration.

\subsection{Effects of user-defined removal upon DO/BOD concentration in framework model}

Since the user-defined removal is applied upon BOD, such user-defined removal levels directly affect the BOD concentration along the reach, yielding the rate of decrease in BOD concentration that seems to increase as a function of distance downstream along the Jordan River. On the other hand, applying such removal upon WWTP and tributary BOD appears to increase the DO concentration, which the improvement in DO concentration seems to increase as the reach distance downstream increases. For instance, for this exercise that employs the Jordan River on August 22, 2012 as a case study, applying an 80\% removal upon BOD for all WWTPs (Jordan Basin, South Valley, Central Valley, South Davis South) with a $50 \%$ removal upon tributary/creek (Little Cottonwood, Big Cottonwood, Millcreek) BOD seems to yield a maximum increase in DO concentration by approximately $2.19 \%$, with the maximum increase from approximately $7.72 \mathrm{mg} / \mathrm{L}$ to $7.89 \mathrm{mg} / \mathrm{L}$, while exhibiting a maximum decrease in BOD by approximately $31.3 \%$, with the maximum decrease from approximately $3.95 \mathrm{mg} / \mathrm{L}$ to $2.72 \mathrm{mg} / \mathrm{L}$.

Meanwhile, such assessments can be further extended toward applying user-defined removal upon point source and tributary inflows (e.g. water quantity). However, such implementations of flow reductions appear to not be recommended and may require significant collaborations with the point sources (e.g. WWTPs) and stakeholders involved with the tributaries. For instance, flow reductions upon tributary inflows suggest the need for implementing stormwater best management practices (BMPs), along with structural BMPs through LowImpact Development (LID), for flood control/flow retention (e.g. detention ponds, rain gardens, etc.). 


\subsection{Implications on BOD/DO WQT}

For this exercise, such removal levels are applied upon the WWTPs and tributaries for implementing a trading scenario among the point (WWTPs) and nonpoint (tributaries) sources. For instance, if levels of removal are applied only to WWTP BOD (e.g. maintaining the tributary BOD inflow), applying high levels of WWTP BOD removal seem to not be as effective as implementing trading between WWTP and tributary based on desired levels of BOD removal. For instance, for this exercise along the Jordan River on August 22, 2012 as a case study, applying nearly 100\% removal (e.g. 99.999\%) upon all point source BOD (e.g. all WWTPs) and no removal upon tributary BOD yields a maximum increase in DO concentration of approximately $1.89 \%$, with a maximum decrease in BOD concentration of approximately $27.2 \%$. In other words, incorporating the removal of tributary BOD while decreasing the levels of removal of point source BOD (e.g. approximately $100 \%$ WWTP BOD removal vs. $80 \%$ WWTP BOD removal) seems to yield greater benefits upon the DO concentrations along the Jordan River as compared to implementing only point source BOD removal, hence suggesting the need for WQT and source loading allocations. Furthermore, these characteristics suggest the need for applying additional removal upon tributary BOD, which such applications implicate the need for implementing stormwater nutrient removal. There are many opportunities for stormwater pollutant removal of biochemical oxygen demand using structural BMPs. On the other hand, uncertainties in BMP performance need to be incorporated and often lead to significant trading ratios.

\section{CONCLUSIONS}

WQT has been shown to be a viable solution to improving surface water quality. While implementation of TMDL remediation plans in the United States may result in expanded WQT markets, these will likely be limited if the focus is solely on addressing improvements of impaired waterways. Policies that value water quality conditions above the minimum are needed to encourage more trading and improve aquatic conditions to more river reaches.

This framework is still conceptual and will require considerably more input from regulators, stakeholders, ecologists, economists, legal experts and time to implement adaptive management strategies. As part of the process, the development of a more detailed processbased water quality model would greatly improve our ability to assess trading and water quality improvements particularly with respect to nutrient impacts on DO. Furthermore, additional work on cold weather BMP performance is needed to better quantify trading between point and non-point treatment remedies.

\section{ACKNOWLEDGEMENTS}

The authors acknowledge the Division of Water Quality from the Utah Department of Environmental Quality for processing and providing inflow quantity and quality data from the original discharge monthly reports of the treatment facilities for Salt Lake County. Such data are provided as part of the University of Utah's Project Number 835866-01 funded by the U.S. Environmental Protection Agency (EPA). This work has not been formally reviewed by EPA. The views expressed in this document are solely those of the authors and do not necessarily reflect those of the Agency. EPA does not endorse any products or commercial services mentioned in this publication. 


\section{REFERENCES}

[1] King, D.M., Crunch time for water quality trading. Choices. American Agricultural Economics Association, 20(1), pp. 71-75, 2005.

[2] Fang, F., Easter, K.W. \& Brezonik, P.L., Point-Nonpoint source water quality trading: A case study for the Minnesota River Basin. JAWRA Journal of the American Water Resources Association, 41(3), pp. 645-658, 2005. https://doi. org/10.1111/j.1752-1688.2005.tb03761.x

[3] Shortle, J. Economics and environmental markets: Lessons from water-quality trading. Agricultural and Resource Economics Review, 42(1), pp. 57-74, 2013. https://doi. org/10.1017/s1068280500007619

[4] Selman, M., Greenhalgh, S., Branosky, E., Jones, C. \& Guiling, J., Water Quality Trading Programs: An International Overview, World Resources Institute: Washington, DC, 2009.

[5] USEPA, Water quality trading toolkit for permit writers. Office of Wastewater Management, EPA 833-R-07-004, Washington, DC, 2009.

[6] Loomis, J., Kent, P., Strange, L., Fausch, K. \& Covich, A., Measuring the total economic value of restoring ecosystem services in an impaired river basin: results from a contingent valuation survey. Ecological Economics, 33(1), pp. 103-117, 2000. https:// doi.org/10.1016/s0921-8009(99)00131-7

[7] Keeler, B.L., Polasky, S., Brauman, K.A., Johnson, K.A., Finlay, J.C., O’Neill, A., Kovacs, K. \& Dalzell, B., Linking water quality and well-being for improved assessment and valuation of ecosystem services. Proceedings of the National Academy of Sciences, 2012. https://doi.org/10.1073/pnas.1215991109

[8] MacDonald, G.K., Jarvie, H.P., Withers, P.J., Doody, D.G., Keeler, B.L., Haygarth, P.M. \& Sharpley, A.N., Guiding phosphorus stewardship for multiple ecosystem services. Ecosystem Health and Sustainability, 12(2), 2016. https://doi.org/10.1002/ehs2.1251

[9] Minnesota Pollution Control Agency, Water quality trading, 2018. https://pca.state. mn.us/water/water-quality-trading (accessed 19 December 2018).

[10] Idaho Department of Environmental Quality, Water quality trading guidance, 2016. https://deq.idaho.gov/media/60179211/water-quality-trading-guidance-1016.pdf (accessed 19 December 2018).

[11] Wisconsin Department of Natural Resources, Guidance for Implementing Water Quality Trading in WPDES Permits, 2014. https://dnr.wi.gov/topic/surfacewater/documents/ WQT_guidance_Aug_21_2013signed.pdf (accessed 4 January 2019).

[12] Mahler, R.L., Simmons, R., Sorensen, F. \& Miner, J.R., Priority water issues in the Pacific Northwest. Journal of Extension, 42(5), 2004. Online, http://joe.org/joe/2004october/ rb3/.php.php

[13] Mahler, R.L. \& Barber, M.E., Using adult education to improve sustainability of water resources in the Pacific Northwest, USA. International Journal of Sustainable Development and Planning, 10(6), pp. 828-842, 2015. https://doi.org/10.2495/sdp-v10-n6-828-842

[14] Utah Division of Water Quality, Prioritizing Utah's 303(d) list, 2016. https://deq.utah. gov/legacy/programs/water-quality/watersheds/docs/2016/303d-list-for\%20tmdl-development.pdf (accessed 19 December 2018).

[15] Scholes, L., Revitt, D.M. \& Ellis, J.B., A systematic approach for the comparative assessment of stormwater pollutant removal potentials. Journal of Environmental Management, 88(3), pp. 467-478, 2008. https://doi.org/10.1016/j.jenvman.2007.03.003

[16] Demetracopoulos, A.C. \& Stefan, H.G., Model of Mississippi River pool: Dissolved oxygen. Journal of Environmental Engineering, 109(5), pp. 1020-1034, 1983. https:// doi.org/10.1061/(asce)0733-9372(1983)109:5(1020) 